\title{
Mastectomy in precision oncology era: myth or reality?
}

\author{
Gianluca Franceschini ${ }^{1}$, Armando Orlandi ${ }^{2}$, Alejandro Martin Sanchez ${ }^{1}$, Maria Alessandra Calegari ${ }^{2}$, \\ Riccardo Masetti ${ }^{1}$
}

${ }^{1}$ Multidisciplinary Breast Unit, Catholic University, Rome, Italy; ${ }^{2}$ Unit of Clinical Oncology, Catholic University, Rome, Italy Correspondence to: Gianluca Franceschini. Multidisciplinary Breast Unit, Catholic University of the Sacred Heart, Largo A. Gemelli, 8, 00168 Rome, Italy. Email: gianlucafranceschini70@gmail.com or franceschinigianluca@gmail.com.

Submitted Jul 26, 2016. Accepted for publication Aug 08, 2016.

doi: $10.21037 /$ tcr.2016.08.26

View this article at: http://dx.doi.org/10.21037/tcr.2016.08.26

We read with great interest the study by van Maaren $e t$ al. recently published in Lancet Oncology (1). This study, conducted on a large Dutch population, shows that breast conservative surgery (BCS) associated with radiotherapy is at least comparable in terms of overall survival to mastectomy. Interestingly, in the subgroup of patients with early stage disease thus with lower prognostic risk (pT1N0), the study reports that mastectomy is even detrimental on survival compared to BCS combined with radiotherapy. Apparently, the lack of exposure to radiation therapy in patients who underwent mastectomy could explain the unfavorable prognostic impact. Although, paradoxically, the benefit of radiation treatment is lost in the subgroups with worst prognosis stage (pT2N0, pT1-2N1), in which the impact of such treatment is expected to be superior. The Authors defend these results in the light of the statistical significance of these data in the multivariate analysis, which includes various factors that may influence the prognosis.

However, in the absence of a biological rationale and given the data inconsistency in respect to the evidences of randomized prospective studies (2-4), we believe that these results may arise from both population selection bias and the lack of essential biological prognostic factors in the multivariate analysis.

Among the selection bias, partially discussed by the Authors, it is evident that the patients enrolled in the mastectomy arm were significantly older. This was to be expected since mastectomy is indicated in small breast tumor in order to limit the exposure to radiation therapy in patients with reduced compliance such as older people. About $14 \%$ of patients in the mastectomy arm were over 79 years old compared to $2 \%$ in the BCS arm. Although the Authors claim to have corrected this selection bias in the multivariate analysis, the age cut-off used for the statistical analysis is not clearly specified. The age cut-off selected could significantly impact on the final statistical result.

Another bias that could explain the unexpected outcome observed by van Maaren $e t$ al. is the absence of stratification for breast cancer biological prognostic factors such as ER, PgR and HER-2 expression and Ki 67 levels. These prognostic factors, despite the limitations connected with their immunohistochemical determination, are routinely used in everyday clinical practice to quantify the risk of recurrence and survival of breast cancers. In spite of this, about $60 \%$ of the population in both groups did not have a valid detection of hormone receptors (ER and $\mathrm{PgR}$ ) and no patient had HER-2 and Ki 67\% determination. Nowadays genetic signatures, mainly based on the expression of these proteins (5) are prospectively validated to significantly impact on breast cancer prognosis. This impact on prognosis appears to be greater especially in small size cancers without lymph node involvement, in which the risk of recurrence is mainly influenced by the metastatic tropism secondary to the genetic and molecular profile of the disease rather than by the stage of the disease.

Thus, an imbalance between the two groups in these factors may determine the incomprehensible detrimental effect of mastectomy in early stage (pT1N0) patients, which is lost in the subgroups of patients with advanced cancer (pT2N0, pT1-2N1) where the disease stage impacts more on survival.

Given these considerations, this large population study allows exclusively to confirm in real-world that BCS plus radiotherapy and mastectomy are equally effective. Whereas, we believe that in the age of precision medicine the results from the subgroup analysis (pT1N0), in the 
absence of biomolecular data, cannot change clinical practice limiting the mastectomy, which currently remains a viable option in selected patients with small tumors.

\section{Acknowledgements}

None.

\section{Footnote}

Provenance: This is a Guest Commentary commissioned by the Section Editor San-Gang Wu (Department of Radiation Oncology, Xiamen Cancer Center, the First affiliated Hospital of Xiamen University, Xiamen, China).

Conflicts of Interest: The authors have no conflicts of interest to declare.

Comment on: van Maaren MC, de Munck L, de Bock GH, et al. 10 year survival after breast-conserving surgery plus radiotherapy compared with mastectomy in early breast cancer in the Netherlands: a population-based study. Lancet Oncol 2016;17:1158-70.

Cite this article as: Franceschini G, Orlandi A, Sanchez AM, Calegari MA, Masetti R. Mastectomy in precision oncology era: myth or reality? Transl Cancer Res 2016;5(S3):S544-S545. doi: 10.21037/tcr.2016.08.26

\section{References}

1. van Maaren MC, de Munck L, de Bock GH, et al. 10 year survival after breast-conserving surgery plus radiotherapy compared with mastectomy in early breast cancer in the Netherlands: a population-based study. Lancet Oncol 2016;17:1158-70.

2. Fisher B, Anderson S, Bryant J, et al. Twenty-year followup of a randomized trial comparing total mastectomy, lumpectomy, and lumpectomy plus irradiation for the treatment of invasive breast cancer. N Engl J Med 2002;347:1233-41.

3. Veronesi U, Cascinelli N, Mariani L, et al. Twentyyear follow-up of a randomized study comparing breastconserving surgery with radical mastectomy for early breast cancer. N Engl J Med 2002;347:1227-32.

4. Litière $S$, Werutsky G, Fentiman IS, et al. Breast conserving therapy versus mastectomy for stage I-II breast cancer: 20 year follow-up of the EORTC 10801 phase 3 randomised trial. Lancet Oncol 2012;13:412-9.

5. Sparano JA, Gray RJ, Makower DF, et al. Prospective Validation of a 21-Gene Expression Assay in Breast Cancer. N Engl J Med 2015;373:2005-14. 